\title{
Vier im Jahre 1896 publicierte altsemitische Siegelsteine.
}

Im verflossenen Jahre sind vier vortrefflich erhaltene altsemitische Siegelsteine abgebildet worden, auf welche ich die Aufmerksamkeit der Leser der Zeitschrift lenken möchte. Der erste derselben ist wahrscheinlich ammonitischer Herkunft. Es ist ein von Prof. R. Brünnow auf seiner Reise nach dem Morgenlande zu 'Ammân erworbenes Siegel aus grünem undurchsichtigen Stein und zuerst in den Mitteilungen und Nachrichten des Deutschen Palästinavereins II (I896), Heft I, S. 4 u. 5 (Abb. 4. 5) abgebildet worden. Nach den dort gegebenen Abbildungen befindet sich in der Mitte des Siegels eine männliche Gestalt mit einer höchst sonderbaren Kopfbedeckung, die einem mit aufwärts verbogenem Schnabel versehenen Thierkopf ähnelt. Auf beiden Seiten steht in altphönicischen Buchstaben die Legende לאלאמץ בן אלשע. Wir erfahren aus dieser Mitteilung gleichzeitig, dass die Inschrift nach Euting's Urteil aus dem 7. vorchr. Jahrhundert stamme. Da diese beiden Abbildungen wenig genügten, so ist der Siegelstein nochmals nach besseren Abdrücken im 2. Heft S. 21 abgebildet worden und zwar in vierfach vergrösserter Autotypie. Danach misst seine Längenachse 0,0I7 m. Es ergiebt sich nunmehr, dass die männliche Gestalt keinerlei Kopfbedeckung trägt. Bart und Haupthaar sind ähnlich wie auf den assyrischen Denkmälern stilisiert. Auch trägt die. Gestalt das von dort her bekannte bis zu den Füssen reichende Gewand. Der Name des Besitzers 
entspricht dem israelitischen Namen המצמ, noch mehr aber interessiert der seines Vaters, da er gleich alttestamentlichem

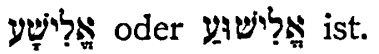

Der zweite Siegelstein ist ein altisraelitischer und neuer dings vom Pariser Cabinet des médailles erworben worden. Ihn hat $\mathrm{Ch}$. Clermont-Ganneau in seinem Aufsatze Notes d'archéologie orientale in der Revue archéologique t. 28 (mai-juin I 896) S. 348-354 abgebildet und besprochen. Er hat eine Längenachse von 0,016 $\mathrm{m}$ und ist durch die bekannten Doppellinien in drei Felder abgeteilt. Das oberste zeigt einen Uraeus mit vier Flügeln und links gewandtem Kopf, das mittelste die Buchstaben ליחמליה, das unterste die Buchstaben iמעיהו und zwar bemerkt. ClermontGanneau ausdrücklich, dass die Lesung der beiden ersten Buchstaben des 3. Feldes sicher sei: „Après les avoir minutieusement examinés à la loupe, et sans parti pris, je ne puis reconnaître dans ces caractères autre chose qu'un waw et un mem". Da ein Siegel nicht zwei Personen gehört, und nicht vorauszusetzen ist, dass der Gottesnamen in beiden Eigennamen in verschiedener Form auftritt, so bleibt nichts übrig als den ersten Buchstaben des 3. Feldes als Schlussbuchstaben zu dem im zweiten Felde stehenden Worte'zu rücken, wofür sich auch Clermont-Ganneau nach einer scharfsinnigen Erörterung aller Möglichkeiten

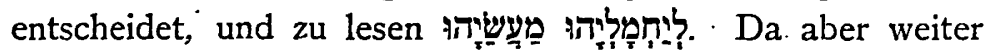
ein Siegel keine Dedikation trägt und nach Analogie des sonst bekannten $ל$ den Besitżer angeben wird, so wird anzunehmen sein, dass zwischen beiden Worten 12 dèr Raumersparniss wegen weggelassen ist, wie das auch bei dem noch zu besprechenden altisraelitischen Siegel der Fall zu sein scheint. Der Name מעשיהו ist aus dem A. T. wohlbekannt, er begegnet uns auch in der abgekürzten Form מַערשֶׁיָה und in dieser auch als Familienname, יחמליהו aber ist neu. 
Dic beiden letzten sind neuerdings vom Königl. Museum zu Berlin erworben und von Ed. Sachau in einer Schlussbemerkung seiner Abhandlung "Aramäische Inschriften" in SBAW 1896, XL. XLI S. 1064 abgebildet und besprochen worden. Sie zeigen wie der von Clermont-Ganneau besprochene Pariser rein ägyptisches Bildwerk. Ihre Legenden zeigen die von der Mesainschrift bekannte älteste Form semitischer Buchstaben. Der grössere (falls die Abbildungen in natürlicher Grösse gegeben sind mit einer Längenachse

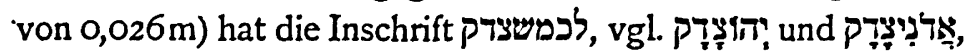
ist also moabitischer Herkunft. Der kleinere (Längenachse bei gleicher Voraussetzung $0,014 \mathrm{~m}$ ) enthält die Legende אחו פקחי, kann also israelitischer Herkunft sein. Auch bei ihm liegt es nahe anzunehmen, dass zwischen beiden Namen iz zu ergänzen ist. Der erste ist aus dem A. T. wohlbekannt. In dem zweiten kann man ebensowohl eine Form auf '. finden,

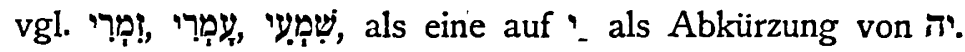
Dann würde es aus dem a. T. T.

Sachau's Abhandlung interessiert auch durch ihren übrigen Inhalt die alttestamentlichen Theologen ebensowohl wie die Archaeologen. An erster Stelle bringt sie die erste vollständige, nach zwei Papierabdrücken gegebene Abbildung und Erklärung der I89I gefundenen, aus den Jahren 73I-727 v: Chr. stammenden Bauinschrift des Königs Barrekûb bar Panammû von Scham'al, die inzwischen nach einem Abklatsch auch J. Halévy in der Revue sémitique IV (I896), S. I85ff. und D. H. Müller in der Wiener Zeitschrift für die Kunde des Morgenlandes X (1896), 3, S. 193-197 abgebildet und erklärt haben. An zweiter Stelle bringt sie eine Abbildung des von $\mathrm{H}$. Burchardt im Drusendorfe Ire aufgefundenen

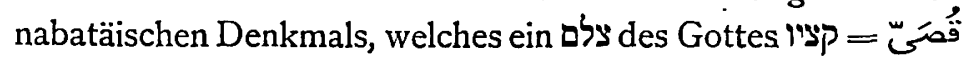
in Stiergestalt zeigt.

B. Stade. 